\title{
Front Matter: Volume 6927
}

, "Front Matter: Volume 6927," Proc. SPIE 6927, Electroactive Polymer Actuators and Devices (EAPAD) 2008, 692701 (2 May 2008); doi: $10.1117 / 12.797944$

Event: SPIE Smart Structures and Materials + Nondestructive Evaluation and Health Monitoring, 2008, San Diego, California, United States 


\title{
PROCEEDINGS OF SPIE
}

\section{Electroactive Polymer Actuators and Devices (EAPAD) 2008}

\author{
Yoseph Bar-Cohen \\ Editor \\ 10-13 March 2008 \\ San Diego, California, USA \\ Sponsored by \\ SPIE \\ Cosponsored by \\ American Society of Mechanical Engineers (USA) \\ Cooperating Organizations \\ Intelligent Materials Forum (Japan) \\ Jet Propulsion Laboratory (USA) \\ National Science Foundation (USA) \\ Published by \\ SPIE
}


The papers included in this volume were part of the technical conference cited on the cover and title page. Papers were selected and subject to review by the editors and conference program committee. Some conference presentations may not be available for publication. The papers published in these proceedings reflect the work and thoughts of the authors and are published herein as submitted. The publisher is not responsible for the validity of the information or for any outcomes resulting from reliance thereon.

Please use the following format to cite material from this book:

Author(s), "Title of Paper," in Electroactive Polymer Actuators and Devices (EAPAD) 2008, edited by Yoseph Bar-Cohen, Proceedings of SPIE Vol. 6927 (SPIE, Bellingham, WA, 2008) Article CID Number.

ISSN 0277-786X

ISBN 9780819471130

Published by

SPIE

P.O. Box 10, Bellingham, Washington 98227-0010 USA

Telephone +1 3606763290 (Pacific Time) · Fax +1 3606471445

SPIE.org

Copyright (C 2008, Society of Photo-Optical Instrumentation Engineers

Copying of material in this book for internal or personal use, or for the internal or personal use of specific clients, beyond the fair use provisions granted by the U.S. Copyright Law is authorized by SPIE subject to payment of copying fees. The Transactional Reporting Service base fee for this volume is $\$ 18.00$ per article (or portion thereof), which should be paid directly to the Copyright Clearance Center (CCC), 222 Rosewood Drive, Danvers, MA 01923. Payment may also be made electronically through CCC Online at copyright.com. Other copying for republication, resale, advertising or promotion, or any form of systematic or multiple reproduction of any material in this book is prohibited except with permission in writing from the publisher. The CCC fee code is $0277-786 \mathrm{X} / 08 / \$ 18.00$.

Printed in the United States of America.

Publication of record for individual papers is online in the SPIE Digital Library.

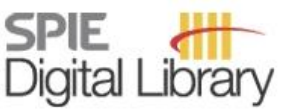

SPIEDigitallibrary.org

Paper Numbering: Proceedings of SPIE follow an e-First publication model, with papers published first online and then in print and on CD-ROM. Papers are published as they are submitted and meet publication criteria. A unique, consistent, permanent citation identifier (CID) number is assigned to each article at the time of the first publication. Utilization of CIDs allows articles to be fully citable as soon they are published online, and connects the same identifier to all online, print, and electronic versions of the publication. SPIE uses a six-digit CID article numbering system in which:

- The first four digits correspond to the SPIE volume number.

- The last two digits indicate publication order within the volume using a Base 36 numbering system employing both numerals and letters. These two-number sets start with 00, 01, 02, 03, 04, 05, $06,07,08,09,0 A, 0 B \ldots 0 Z$, followed by $10-12,20-2 Z$, etc.

The CID number appears on each page of the manuscript. The complete citation is used on the first page, and an abbreviated version on subsequent pages. Numbers in the index correspond to the last two digits of the six-digit CID number. 


\title{
Contents
}

\author{
Symposium Committee \\ Conference Committee \\ Introduction
}

EAP AS EMERGING ACTUATORS AND BIOMIMETIC TECHNOLOGIES

692703 Humanlike robots as platforms for electroactive polymers (EAP) [6927-02]

Y. Bar-Cohen, Jet Propulsion Lab. (USA)

692704 Designing components using smartMOVE electroactive polymer technology [6927-03]

M. Rosenthal, C. Weaber, I. Polyakov, A. Zarrabi, P. Gise, Artificial Muscle, Inc. (USA)

692705 Elastomeric contractile actuators for hand rehabilitation splints [6927-04]

F. Carpi, A. Mannini, D. De Rossi, Univ. of Pisa (Italy)

\section{IONIC/CONDUCTIVE EAP}

692707 Enhancement of the electromechanical transduction properties of a silicone elastomer by blending with a conjugated polymer [6927-06]

F. Carpi, G. Gallone, F. Galantini, D. De Rossi, Univ. of Pisa (Italy)

692708 Carbon nanotube yarns: sensors, actuators, and current carriers [6927-07]

T. Mirfakhrai, Univ. of British Columbia (Canada); M. Kozlov, S. Fang, M. Zhang,

R. H. Baughman, Univ. of Texas at Dallas (USA); J. D. Madden, Univ. of British Columbia

(Canada)

692709 Characterization and modeling of conjugated polymer sensors [6927-08]

Y. Fang, X. Tan, A. Temme, Michigan State Univ. (USA); G. Alici, Univ. of Wollongong

(Australia)

IPMC I

6927 OB IPMC paints [6927-10]

I.-S. Park, R. Tiwari, K. J. Kim, Univ. of Nevada, Reno (USA)

6927 OC Microdeposition method: a novel fabrication method for ionic polymer metallic composites [6927-11]

D. Griffiths, V. B. Sundaresan, Virginia Polytechnic Institute and State Univ. (USA); B. Akle, Lebanese American Univ. (Lebanon); P. Vlachos, D. Leo, Virginia Polytechnic Institute and State Univ. (USA)

6927 OD Ionic polymer-metal composites (IPMCs) with bimetallic Pt-Pd electrode [6927-12]

S.-M. Kim, K. J. Kim, Univ. of Nevada, Reno (USA) 
6927 OE A new force field for molecular dynamics studies of $\mathrm{Li}^{+}$and $\mathrm{Na}^{+}$-nafion [6927-13] E. Soolo, A. Liivat, H. Kasemägi, T. Tamm, Univ. of Tartu (Estonia); D. Brandell, Virginia Polytechnic Institute and State Univ. (USA); A. Aabloo, Univ. of Tartu (Estonia)

6927 OF Application of feedforward dynamics compensation in ionic-polymer metal composite actuators [6927-64]

Y. Shan, K. K. Leang, Virginia Commonwealth Univ. (USA)

6927 OG A distributed model of IPMC [6927-15]

A. Punning, U. Johanson, M. Anton, M. Kruusmaa, A. Aabloo, Tartu Univ. (Estonia)

IPMC II

$6927 \mathrm{OH} \quad$ Extensional ionomeric polymer conductor composite actuators with ionic liquids [6927-93] S. Liu, M. Lin, Q. Zhang, The Pennsylvania State Univ. (USA)

6927 Ol A scalable dynamic model for ionic polymer-metal composite actuators [6927-17]

Z. Chen, X. Tan, Michigan State Univ. (USA)

6927 OJ A correlation between extensional displacement and architecture of ionic polymer transducers [6927-18]

B. J. Akle, Lebanese American Univ. (Lebanon); A. Duncan, D. J. Leo, Virginia Polytechnic Institute and State Univ. (USA)

6927 OK Frequency response of anisotropic ionic polymer metal composites (IPMC) transducers [6927-19]

B. L. Stoimenov, RIKEN (Japan); J. Rossiter, Univ. of Bristol (United Kingdom); T. Mukai, RIKEN (Japan); K. Asaka, AIST (Japan)

$6927 \mathrm{OL}$ The effect of IPMC parameters in electromechanical coefficient based on equivalent beam theory [6927-20]

H. D. Çilingir, Y. Menceloglu, M. Papila, Sabancı Univ. (Turkey)

\section{DIELECTRIC EAP ACTUATORS I}

6927 OM Accomplishments and future trends in the field of electroactive polymers (Invited Paper) [6927-21]

A. M. Vinogradov, Montana State Univ. (USA)

692700 Polyaniline nanofibers as a novel electrode material for fault-tolerant dielectric elastomer actuators [6927-23]

T. Lam, H. Tran, W. Yuan, Z. Yu, S. Ha, R. Kaner, Q. Pei, Univ. of California, Los Angeles (USA)

6927 OP Self-clearable carbon nanotube electrodes for improved performance of dielectric elastomer actuators [6927-24]

W. Yuan, L. Hu, S. Ha, T. Lam, G. Grüner, Q. Pei, Univ. of California, Los Angeles (USA) 
6927 OQ Cellular ferroelectrets for electroactive polymer hybrid systems: soft matter integrated devices with advanced functionality (Invited Paper) [6927-25]

R. Schwödiaver, I. Graz, M. Kaltenbrunner, C. Keplinger, P. Bartu, G. Buchberger,

C. Ortwein, S. Baver, Johannes Kepler Univ. (Austria)

6927 OR A dielectric electroactive polymer generator-actuator model: modeling, identification, and dynamic simulation [6927-26]

C. M. Ihlefeld, NASA Kennedy Space Ctr. (USA); Z. QU, Univ. of Central Florida (USA)

6927 OS Feasibility studies for a bionic propulsion system of a blimp based on dielectric elastomers (Invited Paper) [6927-27]

S. Michel, Swiss Federal Labs. for Materials Testing and Research (Switzerland); A. Bormann, AeroiX (Germany); C. Jordi, Swiss Federal Labs. for Materials Testing and Research (Switzerland); E. Fink, Technical Univ. Berlin (Germany)

6927 ОT An experimentally validated model of a dielectric elastomer bending actuator [6927-28] B. O'Brien, Univ. of Auckland (New Zealand); E. Calius, Industrial Research Ltd. (New Zealand); S. Xie, I. Anderson, Univ. of Auckland (New Zealand)

6927 OV A dielectric elastomer actuator with self-sensing capability [6927-63] N. Huu Chuc, D. V. Thuy, J. Park, D. Kim, J. Koo, Y. Lee, J.-D. Nam, H. R. Choi, Sungkyunkwan Univ. (South Korea)

6927 OW Ion-implanted compliant and patternable electrodes for miniaturized dielectric elastomer actuators [6927-30]

S. Rosset, M. Niklaus, V. Stojanov, A. Felber, P. Dubois, H. R. Shea, École Polytechnique Fédérale de Lausanne (Switzerland)

6927 OX Study on core free rolled actuator based on soft dielectric EAP [6927-31]

G. Kovacs, Swiss Federal Labs. for Materials Testing and Research (Switzerland); S. M. Ha, Univ. of California, Los Angeles (USA); S. Michel, Swiss Federal Labs. for Materials Testing and Research (Switzerland); R. Pelrine, SRI International (USA); Q. Pei, Univ. of California, Los Angeles (USA)

\section{MODELING AND SIMULATION}

6927 OY Coupled chemo-electro-mechanical simulation of polyelectrolyte gels as actuators and sensors [6927-32]

T. Wallmersperger, D. Ballhause, B. Kröplin, Univ. Stuttgart (Germany); M. Günther, Z. Shi,

G. Gerlach, Technische Univ. Dresden (Germany)

$69270 Z$ Redox level-dependent impedance model for conjugated polymer actuators [6927-70] Y. Fang, X. Tan, Michigan State Univ. (USA); G. Alici, Univ. of Wollongong (Australia)

692710 A theory of large deformation in soft active materials [6927-34] Z. SUo, X. Zhao, W. Hong, Harvard Univ. (USA); J. Zhou, Harvard Univ. (USA) and Xi'an Jiaotong Univ. (China); W. H. Greene, Coventor Inc. (USA) 
692711 An advanced finite element model of IPMC [6927-35]

D. Pugal, H. Kasemägi, M. Kruusmaa, A. Aabloo, Tartu Univ. (Estonia)

692712 Modelling electroactive polymer (EAP) actuators: electro-mechanical coupling using finite element software [6927-36]

F. Rosenblatt, J. F. Morrison, L. Iannucci, Imperial College London (United Kingdom)

ENERGY HARVESTING USING EAP

692713 Overview on energy harvesting and storage systems (EHSS) for future AF vehicles (Invited Paper) [6927-37]

M. Taya, C. XU, M. Nagata, Univ. of Washington (USA)

692714 Electrolyte for laminated polymer lithium rechargeable battery [6927-38]

C. XU, C. Ma, M. Taya, Univ. of Washington (USA)

692715 Innovative power generators for energy harvesting using electroactive polymer artificial muscles [6927-39]

S. Chiba, SRI International (USA); M. Waki, Hyper Drive Corp. (Japan); R. Kornbluh, R. Pelrine, SRI International (USA)

692716 Dielectric polymer: scavenging energy from human motion [6927-40]

C. Jean-Mistral, CEA-LETI-Minatec (France); S. Basrour, TIMA (France); J.-J. Chaillout, CEA-LETI-Minatec (France)

692717 Improving electrical conductivity by forming Ni powder chains in a shape-memory polymer filled with carbon black [6927-41]

X. Lan, Harbin Institute of Technology (China); W. M. Huang, N. Liu, S. Phee, Nanyang Technological Univ. (Singapore); J. S. Leng, S. Y. Du, Harbin Institute of Technology (China)

692718 Design of dye-sensitized solar cells with new light-harvesting dyes [6927-42]

M. Nagata, Univ. of Washington (USA); M. Kimura, Shinshu Univ. (Japan); M. Taya, Univ. of Washington (USA)

\section{APPLICATION OF EAP TO ROBOTICS}

6927 1A Inflated dielectric elastomer actuator for eyeball's movements: fabrication, analysis and experiments [6927-65]

Y. Liu, L. Shi, L. Liu, Z. Zhang, J. Leng, Harbin Institute of Technology (China)

6927 1B Bio-inspired tactile sensor with arrayed structures based on electroactive polymers [6927-44]

J. Wang, C. Xu, M. Taya, Y. Kuga, Univ. of Washington (USA)

6927 1C An adaptive control method for dielectric elastomer devices [6927-45]

T. A. Gisby, Univ. of Auckland (New Zealand); E. P. Calius, Industrial Research Ltd. (New Zealand); S. Xie, I. A. Anderson, Univ. of Auckland (New Zealand) 
6927 1D Potential of thermally expandable polymers with embedded skeletons for actuator applications [6927-47]

G.-K. Lau, Nanyang Technological Univ. (Singapore); J. F. L. Goosen, T. Chu Duc,

F. van Keulen, Delft Univ. of Technology (Netherlands)

6927 IE The application of polypyrrole trilayer actuators in microfluidics and robotics [6927-48]

R. Kiefer, X. Mandviwalla, R. Archer, S. S. Tjahyono, H. Wang, B. MacDonald,

G. A. Bowmaker, P. A. Kilmartin, J. Travas-Sejdic, Univ. of Auckland (New Zealand)

6927 IF An electroactive polymer based concept for vibration reduction via adaptive supports [6927-49]

K. Wolf, T. Röglin, Technische Univ. Darmstadt (Germany); F. Haase, Fraunhofer Institute for Structural Durability and System Reliability (Germany); T. Finnberg, B. Steinhoff, German Institute for Polymers (Germany)

6927 1G Plastic Muscles as lightweight low voltage actuators and sensors [6927-50]

M. Bennett, Discover Technologies, Inc. (USA); D. Leo, A. Duncan, Virginia Polytechnic Institute and State Univ. (USA)

\section{OTHER EAP}

$69271 \mathrm{H} \quad$ Cellulose-chitosan blend electroactive paper actuator [6927-51]

Z. Cai, Y. Chen, J. Kim, Inha Univ. (South Korea)

692711 The development of electrically driven mechanochemical actuators that act as artificial muscle [6927-52]

L. Rasmussen, Ras Labs., LLC (USA); L. Meixler, Princeton Plasma Physics Lab. (USA);

D. Harper, K. Park, TRI/Princeton (USA)

\section{APPLICATIONS OF EAP TO OPTICAL DEVICES}

$69271 \mathrm{~J} \quad$ Smart sunglasses with tunable shade [6927-54]

C. Ma, M. Taya, C. XU, Univ. of Washington (USA)

6927 IK Design and position control of AF lens actuator for mobile phone using IPMC-EMIM [6927-55]

S.-J. Kim, C.-J. Kim, N.-C. Park, H.-S. Yang, Y.-P. Park, Yonsei Univ. (South Korea); K.-H. Park,

H.-K. Lee, N.-J. Choi, Electronics and Telecommunications Research Institute (South Korea)

6927 1L Fast bender actuators for fish-like aquatic robots [6927-91]

S. T. McGovern, G. M. Spinks, B. Xi, Univ. of Wollongong (Australia) and ARC Ctr. for Electromaterials Science (Australia); G. Alici, Univ. of Wollongong (Australia); V. Truong, Defence Science and Technology Organisation (Australia); G. G. Wallace, Univ. of Wollongong (Australia) and ARC Ctr. for Electromaterials Science (Australia)

$69271 \mathrm{M}$ Development of a dry actuation conducting polymer actuator for micro-optical zoom lenses [6927-57]

B.-K. Kim, H. Kim, H. C. Nguyen, M. S. Cho, Y. Lee, J.-D. Nam, H. R. Choi, J. C. Koo, Sungkyunkwan Univ. (South Korea); H.-S. Jeong, Samsung Electro-Mechanics (South Korea) 
6927 iN Application of ionic polymer-metal composites for auto-focusing compact camera modules [6927-58]

H.-K. Lee, N.-J. Choi, S. Jung, S. Lee, Electronics and Telecommunications Research Institute (South Korea); H. Jung, J. W. Ryu, Hysonic Co., Ltd. (South Korea); K.-H. Park, Electronics and Telecommunications Research Institute (South Korea)

\section{APPLICATIONS OF EAP TO ACTUATION AND TRANSDUCTION}

6927 IP Nonlinear dynamic characteristics of dielectric elastomer membranes [6927-60]

J. W. Fox, N. C. Goulbourne, Virginia Polytechnic Institute and State Univ. (USA)

$69271 Q$ Optimization of active electrodes for novel ionomer-based ionic polymer transducers [6927-61]

A. J. Duncan, S. A. Sarles, D. J. Leo, T. E. Long, Virginia Polytechnic Institute and State Univ. (USA); B. J. Akle, Lebanese American Univ. (Lebanon); M. D. Bennett, Discover Technologies, Inc. (USA)

\section{POSTER SESSION}

6927 IR Tunable transmission grating based on dielectric elastomer actuators [6927-56]

M. Aschwanden, D. Niederer, A. Stemmer, ETH Zurich (Switzerland)

6927 is Self-sensing of dielectric elastomer actuator [6927-66]

K. Jung, K. J. Kim, Univ. of Nevada, Reno (USA); H. R. Choi, Sungkyunkwan Univ. (South Korea)

6927 IT Frequency response of polypyrrole trilayer actuator displacement [6927-67]

S. John, G. Alici, C. Cook, Univ. of Wollongong (Australia)

$69271 \mathrm{U}$ Porous conductive polyblends of polyaniline in poly(methyl methacrylate) [6927-85]

A. D. Price, H. E. Naguib, Univ. of Toronto (Canada)

6927 IV A double-sided electret polymer film-based electrostatic actuator [6927-72]

W.-C. Ko, J.-L. Chen, W.-J. Wu, National Taiwan Univ. (Taiwan); C.-K. Lee, National Taiwan Univ. (Taiwan) and Industrial Technology Research Institute (Taiwan)

6927 IW Electromechanical simulation of cellulose based biomimetic electro-active actuator [6927-73]

S. Jang, Inha Univ. (South Korea); H. S. Kim, Inha Univ. (South Korea) and Catholic Univ. of Daegu (South Korea); J. Kim, Inha Univ. (South Korea); P. Basappa, Norfolk State Univ. (USA)

6927 1X Novel electro-active polymer actuator based on ionic networking membrane of PSMIincorporated PVDF [6927-74]

J. Lu, Chonnam National Univ. (South Korea); S.-G. Kim, Korea Research Institute of Chemical Technology (South Korea); S. Lee, I.-K. Oh, Chonnam National Univ. (South Korea)

6927 IY Self-healing properties of Cu-Pt coated ionic polymer actuators [6927-75]

U. Johanson, A. Punning, M. Kruusmaa, A. Aabloo, Tartu Univ. (Estonia) 
692712 A multilink manipulator with IPMC joints [6927-76]

A. Hunt, A. Punning, M. Anton, A. Aabloo, M. Kruusmaa, Tartu Univ. (Estonia)

692720 Electrochemomechanical behaviour of free standing PEDOT films in organic and aqueous electrolytes [6927-77]

R. Kiefer, P. A. Kilmartin, G. A. Bowmaker, J. Travas-Sejdic, Univ. of Auckland (New Zealand)

692721 Sensor response of polypyrrole trilayer benders as a function of geometry [6927-79]

S. John, G. Alici, G. Spinks, Univ. of Wollongong (Australia); J. D. W. Madden, Univ. of British Columbia (Canada); G. G. Wallace, Univ. of Wollongong (Australia)

692722 High-precision characterization of dielectric elastomer stack actuators and their material parameters [6927-80]

M. Matysek, P. Lotz, K. Flittner, H. F. Schlaak, Darmstadt Univ. of Technology (Germany)

692723 Dielectric elastomer actuators using improved thin film processing and nanosized particles [6927-81]

P. Lotz, M. Matysek, P. Lechner, M. Hamann, H. F. Schlaak, Darmstadt Univ. of Technology (Germany)

692724 Frequency response characteristics of IPMC sensors with current/voltage measurements [6927-82]

K. Takagi, Nagoya Univ. (Japan) and RIKEN (Japan); N. Kamamichi, Tokyo Denki Univ. (Japan) and RIKEN (Japan); B. Stoimenov, RIKEN (Japan); K. Asaka, AIST (Japan) and RIKEN (Japan); T. Mukai, RIKEN (Japan); Z.-W. Luo, Kobe Univ. (Japan) and RIKEN (Japan)

692725 Preisach modeling of IPMC-EMIM actuator [6927-83]

C.-J. Kim, H. W. Hwang, N.-C. Park, H.-S. Yang, Y.-P. Park, Yonsei Univ. (South Korea); K.-H. Park, H.-K. Lee, N.-J. Choi, Electronics and Telecommunications Research Institute (South Korea)

692726 Preisach modeling of dielectric elastomer EAP actuator [6927-84]

H. Hwang, C.-J. Kim, S. J. Kim, H. Yang, N. C. Park, Y.-P. Park, Yonsei Univ. (South Korea)

$692727 \quad$ Molecular dynamics studies of interpenetrating polymer networks for actuator devices [6927-69]

D. Brandell, Virginia Polytechnic Institute and State Univ. (USA); H. Kasemägi, Tartu Univ. (Estonia); J. Citérin, Lab. Systèmes Complexes, CNRS, Univ. d'Evry (France); F. Vidal,

C. Chevrot, Univ. Cergy-Pontoise (France); A. Aabloo, Tartu Univ. (Estonia)

692728 Classification and selection of actuator technologies with consideration of stimuli generation [6927-86]

A. Poole, J. D. Booker, Univ. of Bristol (United Kingdom)

6927 2A Electric field around a dielectric elastomer actuator in proximity to the human body [6927-88]

A. C. McKenzie, Univ. of Auckland (New Zealand); E. P. Calius, Industrial Research Ltd. (New Zealand); I. A. Anderson, Univ. of Auckland (New Zealand) 
6927 2C High electromechanical performance of electroelastomers based on interpenetrating polymer networks [6927-90]

S. M. Ha, Univ. of California, Los Angeles (USA); I. S. Park, Univ. of Nevada, Reno (USA); M. Wissler, Empa (Switzerland); R. Pelrine, S. Stanford, SRI International (USA); K. J. Kim, Univ. of Nevada, Reno (USA); G. Kovacs, Empa (Switzerland); Q. Pei, Univ. of California, Los Angeles (USA)

6927 2D Architecture for the semi-automatic fabrication and assembly of thin-film based dielectric elastomer actuators [6927-92]

M. Randazzo, Italian Institute of Technology (Italy) and Univ. of Genova (Italy); R. Buzio, Nanomed Labs. (Italy) and Univ. of Genova (Italy); G. Metta, G. Sandini, Italian Institute of Technology (Italy) and Univ. of Genova (Italy); U. Valbusa, Nanomed Labs. (Italy) and Univ. of Genova (Italy)

Author Index 


\title{
Symposium Committee
}

\author{
Symposium Chairs
}

Alison B. Flatau, University of Maryland, College Park (USA)

George Y. Baaklini, NASA Glenn Research Center (USA)

Donald J. Leo, Virginia Polytechnic Institute and State University (USA)

Kara J. Peters, North Carolina State University (USA)

Executive Committee

Alison B. Flatau, University of Maryland, College Park (USA)

George Y. Baaklini, NASA Glenn Research Center (USA)

Donald J. Leo, Virginia Polytechnic Institute and State University (USA)

Kara J. Peters, North Carolina State University (USA)

Mehdi Ahmadian, Virginia Polytechnic Institute and State University (USA)

Yoseph Bar-Cohen, Jet Propulsion Laboratory (USA)

Emilio P. Calius, Industrial Research Ltd. (New Zealand)

Marcelo J. Dapino, The Ohio State University (USA)

L. Porter Davis, Honeywell, Inc. (USA)

Michael A. Demetriou, Worcester Polytechnic Institute (USA)

Aaron A. Diaz, Pacific Northwest National Laboratory (USA)

Wolfgang Ecke, IPHT Jena (Germany)

Mehrdad N. Ghasemi-Nejhad, University of Hawai'i at Manoa (USA)

Victor Giurgiutiu, University of South Carolina (USA)

B. Kyle Henderson, Air Force Research Laboratory (USA)

Kumar V. Jata, Air Force Research Laboratory (USA)

Tribikram Kundu, The University of Arizona (USA)

Douglas K. Lindner, Virginia Polytechnic Institute and State University (USA)

Ajit K. Mal, University of California, Los Angeles (USA)

M. Brett McMickell, Honeywell, Inc. (USA)

Norbert G. Meyendorf, Fraunhofer-Institut für Zerstörungsfreie

Prüfverfahren (Germany) and University of Dayton (USA)

Zoubeida Ounaies, Texas A\&M University (USA)

Andrei M. Shkel, University of California, Irvine (USA)

Peter J. Shull, The Pennsylvania State University (USA)

Masayoshi Tomizuka, University of California, Berkeley (USA)

Vijay K. Varadan, University of Arkansas (USA)

Dietmar W. Vogel, Fraunhofer-Institut für Zuverlässigkeit und Mikrointegration (Germany)

H. Felix Wu, National Institute of Standards and Technology (USA)

Chung-Bang Yun, Korea Advanced Institute of Science and Technology

(South Korea) 
Downloaded From: https://www.spiedigitallibrary.org/conference-proceedings-of-spie on 26 Apr 2023

Terms of Use: https://www.spiedigitallibrary.org/terms-of-use 


\title{
Conference Committee
}

\author{
Conference Chair
}

Yoseph Bar-Cohen, Jet Propulsion Laboratory (USA)

Conference Cochair

Emilio P. Calius, Industrial Research Ltd. (New Zealand)

Program Committee

Ray H. Baughman, The University of Texas at Dallas (USA)

Václav Bouda, Czech Technical University in Prague (Czech Republic)

Federico Carpi, University of Pisa (Italy)

Danilo De Rossi, University of Pisa (Italy)

Toribio Fernandez-Otero, Technical University of Cartagena (Spain)

Edwin W. H. Jager, Micromuscle AB (Sweden)

Keiichi Kaneto, Kyushu Institute of Technology (Japan)

Jaehwan Kim, Inha University (South Korea)

Kwang J. Kim, University of Nevada, Reno (USA)

Gabor M. Kovacs, EMPA (Switzerland)

Roy D. Kornbluh, SRI International (USA)

Jinsong Leng, Harbin Institute of Technology (China)

Wen-Liang Liu, Industrial Technology Research Institute (Taiwan)

John D. W. Madden, The University of British Columbia (Canada)

Chris Melhuish, University of Bristol (United Kingdom)

Jaedo Nam, Sungkyunkwan University (South Korea)

Siavouche Nemat-Nasser, University of California, San Diego (USA)

Yoshihito Osada, Hokkaido University (Japan)

Qibing Pei, University of California, Los Angeles (USA)

Subramaniam Radhakrishnan, National Chemical Laboratory (India)

Mohsen Shahinpoor, Environmental Robots, Inc. (USA)

Elisabeth Smela, University of Maryland, College Park (USA)

Peter Sommer-Larsen, Technical University of Denmark (Denmark)

Ji Su, NASA Langley Research Center (USA)

Minoru Taya, University of Washington (USA)

Gordon G. Wallace, University of Wollongong (Australia)

Thomas Wallmersperger, University Stuttgart (Germany)

Gary Zaiats, RAFAEL Armament Development Authority Ltd. (Israel)

Qiming Zhang, The Pennsylvania State University (USA)

Session Chairs

EAP as Emerging Actuators and Biomimetic Technologies

Yoseph Bar-Cohen, Jet Propulsion Laboratory (USA)

Emilio P. Calius, Industrial Research Ltd. (New Zealand) 
Ionic, Conductive EAP

Federico Carpi, University of Pisa (Italy)

Tissaphern Mirfakhrai, The University of British Columbia (Canada)

IPMC I

Kwang J. Kim, University of Nevada, Reno (USA)

Jinsong Leng, Harbin Institute of Technology (China)

IPMC II

Donald J. Leo, Defense Advanced Research Projects Agency (USA)

Silvain A. Michel, EMPA (Switzerland)

Dielectric EAP Actuators I

Barbar J. Akle, Lebanese American University (Lebanon)

Geoffrey M. Spinks, University of Wollongong (Australia)

Dielectric EAP Actuators II

Aleksandra M. Vinogradov, Montana State University, Bozeman (USA)

Silvain A. Michel, EMPA (Switzerland)

Modeling and Simulation

Thomas Wallmersperger, University Stuttgart (Germany)

Xuanhe Zhao, Harvard University (USA)

Energy Harvesting using EAP

Minoru Taya, University of Washington (USA)

Roy D. Kornbluh, SRI International (USA)

Application of EAP to Robotics

Reinhard Schwödiauer, Johannes Kepler University Linz (Austria)

Gordon G. Wallace, University of Wollongong (Australia)

Other EAP

Jaehwan Kim, Inha University (South Korea)

Siavouche Nemat-Nasser, University of California, San Diego (USA)

Applications of EAP to Optical Devices

Hyouk Ryeol Choi, Sungkyunkwan University (South Korea)

Iain A. Anderson, The University of Auckland (New Zealand)

Applications of EAP to Actuation and Transduction

Reinhard Schwödiauer, Johannes Kepler University Linz (Austria)

Emilio P. Calius, Industrial Research Ltd. (New Zealand) 


\section{Introduction}

The large displacement that can be produced by EAP materials and their functional similarity to biological muscles are increasingly attracting the interest of researchers from many fields. Turning these materials into actuators-of-choice continues to require solidifying the technical foundations. Also, it is essential to identify niche applications for EAP materials where their unique capabilities would provide an edge for critical needs. SPIE's Electroactive Polymers Actuators and Devices (EAPAD) conference serves as the leading international forum for presenting the latest progress and discussions among the attendees regarding the capabilities, challenges, and potential future directions.

The keynote speaker was Adam P. Summers, University of California, Irvine, and the title of his presentation was "High-performance with a 'soft' skeleton: the shark cartilage composite." This presentation gave the attendees details about the fascinating capability of sharks to swim at high speed and maneuverability using controlled body pressure. The presentation provided the audience ideas for making future robotic fish using EAP. This paper tied well with the EAP-in-Action Session where the EMPA's blimp was demonstrated with enhanced capability to be steered by Dielectric Elastomer EAP strips on its four fins. This blimp is being developed at EMPA, Switzerland, toward propelling it in the air by a wagging tail and a body that bends like a fish. The EAP-in-Action Session was held on Monday 10 March, and it included 8 demonstrations by organizations from Australia, China, Italy, New Zealand, Switzerland, and the USA. The presenters included Artificial Muscle, Inc.; Auckland Biomimetics Laboratory Bioengineering Institute, and Industrial Research Ltd. (New Zealand); Hyper Drive Corporation (Japan) and SRI International; Materials Science \& Technology, EMPA, (Switzerland); Harbin Institute of Technology (China); Optotune, Zürich (Switzerland); Research Centre "E. Piaggio", University of Pisa (Italy); and University of Wollongong (Australia).

The conference program this year included 85 presentations and was well attended by leading world experts in the field including members of academia, industry, and government agencies from the USA and overseas. Significant progress was reported in each of the topics of the EAP infrastructure. The papers focused on issues that can forge the transition to practical use, including improved materials, better understanding of the principles responsible for the electromechanical behavior, analytical modeling, processing and characterization methods, as well as considerations and demonstrations of various applications. A special session dedicated to the issue of energy harvesting covered the use of EAP materials and solar energy, and vibration conversion. 
Papers in this conference covered the following topics:

- Electroactive polymers (EAP) and non-electro active-polymer (NEAP) materials

- Theoretical models, analysis, and simulation of EAP

- Methods of testing and characterization of EAP

- EAP as artificial muscles, actuators, and sensors

- Design, control, intelligence, and kinematic issues related to robotic and biomimetic operation of EAP

- Under consideration and in progress applications of EAP.

The efforts described in the presented papers are showing significant improvements in understanding of the electromechanical principles and better methods of dealing with the challenges to the materials applications. Researchers are continuing to develop analytical tools and theoretical models to describe the electro-chemical and-mechanical processes, nonlinear behavior, as well as methodologies of design and control of the activated materials. EAP with improved response were described including electrostrictive, IPMC, dielectric, carbon nanotubes, conductive polymers, and other types. Also, the IPMC challenge of the need to maintain wetness was addressed using nonwater-based electrolyte and efforts were made to deal with the high voltage requirement to drive the field activable (i.e., electronic) group.

To provide the attendees with opportunity to learn about EAP, an introductory course was given on Sunday 9 March as part of the EAPAD conference. The course was entitled "Electroactive Polymer Actuators and Devices," and the lead instructor was the conference chair, Yoseph Bar-Cohen, who presented an overview, and covered applications that are currently developed and ones that are being considered. The subject of ionic EAP was covered by Kwang Kim from the University of Nevada-Reno. Further, the topic of electronic EAP was covered by Qibing Pei from the University of California at Los Angeles. This course was intended for engineers, scientists and managers who need to understand the basic concepts of EAP, or are interested in learning, applying or engineering mechanisms or devices using EAP materials. Also, it was intended for those who are considering research and development in EAP materials and their present and/or future applications. For those who are seeking to self-learn about EAP, comprehensive coverage of the topic is given in the book Electroactive Polymer (EAP) Actuators as Artificial Muscles-Reality, Potential, and Challenges (SPIE Press, 2nd ed., http://ndeaa.jpl.nasa.gov/nasa-nde/yosi/yosi-books.htm, as well as the WW-EAP webhub: (http://eap.jpl.nasa.gov) with links to the leading research and development labs worldwide, and the WW-EAP Newsletter.

In closing, I would like to extend a special thanks to all the conference attendees, session chairs, the EAP-in-Action demo presenters, the members of the EAPAD program organization committee and my cochair, Emilio P. Calius, Industrial 
Research Ltd., New Zealand. In addition, special thanks are extended to the SPIE staff that helped making this conference a great success.

Yoseph Bar-Cohen 
Downloaded From: https://www.spiedigitallibrary.org/conference-proceedings-of-spie on 26 Apr 2023

Terms of Use: https://www.spiedigitallibrary.org/terms-of-use 